\title{
Relacionamento Entre Multinacionais e Parceiros na Perspectiva de Inovações em Gestão na Cadeia de Valor
}

\author{
http://dx.doi.org/10.21527/2237-6453.2019.46.25-44 \\ Recebido em: 8/8/2016 \\ Aceito em: $18 / 4 / 2018$
}

Sirlei Pitteri ${ }^{1}$, Paulo Roberto Feldmann ${ }^{2}$

\begin{abstract}
RESUMO
Este estudo teve como objetivo analisar as possíveis relações entre competências territoriais e inovações em gestão na cadeia de valor, em polos econômicos formados nos entornos de corporações multinacionais. Inovação em gestão, nesse contexto, concentra-se na evolução dos processos decorrentes da interação entre as empresas, na perspectiva de quatro dimensões: relações eficazes entre empresas; flexibilidade nas práticas de gestão internas e externas; preservação de recursos esgotáveis e do meio ambiente; geração de conhecimento e aprendizagem interativa. Trata-se de estudo teórico-empírico, exploratório, essencialmente qualitativo. Inicialmente foi construído um modelo teórico-metodológico que fundamentou as análises da pesquisa empírica, em que foram utilizadas duas abordagens metodológicas em três etapas distintas. Os resultados apontam que as relações entre as multinacionais e seus parceiros vêm se consolidando, especialmente na dimensão geração de conhecimento e aprendizagem interativa. O modelo conceitual mostrou-se adequado para análises de comportamento inovativo na cadeia de valor e pode ser adotado em estudos futuros para se efetuar análises comparativas entre as regiões.
\end{abstract}

Palavras-chave: Competências territoriais. Inovações em gestão. Relacionamento entre organizações. Aprendizagem interativa.

\section{RELATIONSHIP BETWEEN MAULTINATIONALS AND PARTNES REGARDING MANAGEMENT INNOVATIONS ON THE VALUE CHAIN}

\begin{abstract}
This study aimed to analyze the possible relationships between territorial competencies and management innovations on the value chain, in economic poles formed in the environments of multinational corporations. Innovation in management, in this context, focuses on the evolution of processes arising from the interaction between companies, from the perspective of four dimensions: effective relationships between companies; flexibility in internal and external management practices; preservation of exhaustible resources and environment and generation of knowledge and interactive learning. It is a theoretical-empirical study, exploratory, essentially qualitative. Initially, a conceptual model was built that based the empirical research analyzes, in which two methodological approaches were used in three distinct stages. The results show that the relationships between the multinationals and their partners have been consolidating, especially in the dimension of knowledge generation and interactive learning. The conceptual model was suitable for analysis of innovative behavior in the value chain and can be adopted in future studies to carry out comparative analyzes between regions.
\end{abstract}

Keywords: Territorial competencies. Management innovation. Inter-organizational relationship. Interactive learning.

\footnotetext{
${ }^{1}$ Pós-doutora em Administração pela Faculdade de Economia, Administração e Contabilidade da Universidade de São Paulo. Professora na Universidade Paulista. sirleipitteri@usp.br

${ }^{2}$ Doutor em Administração pela Fundação Getúlio Vargas, professor do Programa de Pós-Graduação em Administração da Faculdade de Economia, Administração e Contabilidade da Universidade de São Paulo. feldmann@usp.br
} 
Os territórios produtivos, formados ao longo do século passado, apresentavam uma lógica de organização baseada no binômio industrialização-urbanização por conta dos movimentos migratórios, antes absorvidos pelas indústrias, especialmente aquelas que se caracterizavam pela contratação de trabalhadores não qualificados. Sob os efeitos da globalização, contudo, as três últimas décadas vêm registrando acentuadas modificações no perfil dos empregos, provocando um descompasso entre a crescente necessidade de força de trabalho qualificada e o aumento do desemprego da população desqualificada.

Essa tendência confirmou-se em pesquisa realizada por Dedecca, Montali e Baeninger (2009), em que a dinâmica socioeconômica paulista não se associa mais à dualidade região metropolitana-interior, prevalecente até a década de 70. A instalação de bases industriais em diversas regiões do interior do Estado e o revigoramento da atividade agrícola induziram um processo de transformação da configuração econômica e social do interior do Estado, resultando em progressiva metropolização, bem como na constituição de diversos polos econômicos com alguma integração e especialização no espaço local.

Os movimentos de atração de empresas multinacionais para o interior paulista, ao longo dos últimos 15 anos (2000-2015), provavelmente geraram transformações e novas dinâmicas de relacionamento entre os atores presentes nos territórios, conforme se constatou no estudo elaborado por Pitteri, Feldmann e Bresciani (2014) no qual, quando as corporações transnacionais buscam territórios para se expandirem, migram para localidades com características muito diferentes das dos seus países nativos. As forças locais manifestadas por meio dos sistemas econômicos, sociais, políticos e culturais, que se formaram ao longo de suas histórias, constituem um contexto singular para cada território, região ou comunidade.

Dicken (2010) propõe que se faça uma reflexão sobre a simetria (ou assimetria) entre as forças globais e as locais presentes no processo. As forças globais podem ser traduzidas como o grau de integração funcional das atividades econômicas que a empresa pretende adotar e as forças locais representam o alcance da expansão geográfica para as suas atividades econômicas.

Assim, a proposição inicial deste estudo é que a instalação de grandes corporações multinacionais no interior paulista gerou transformações, provocando novas dinâmicas de relacionamento, envolvendo empresas, governos, centros de pesquisas, entidades de classes, sindicatos e a sociedade em geral.

O objetivo geral do estudo situa-se em analisar as relações entre a geração de competências territoriais e a produção de inovação que contribuem para o desenvolvimento sustentável das localidades. A ideia de inovação nesse contexto concentra-se na interação entre as empresas multinacionais e seus parceiros, na perspectiva de quatro dimensões de inovação: relações eficazes entre empresas; flexibilidade nas práticas de gestão internas e externas; preservação de recursos esgotáveis e do meio ambiente e aprendizagem interativa. 
Essa abordagem desenvolveu-se a partir do conceito de competências territoriais, proposto por Pitteri e Bresciani (2015), e possíveis pontos de contato com inovações em gestão, cujas tendências foram identificadas em dois estudos relacionados às práticas inovativas empresariais.

A primeira tendência foi constatada em estudo elaborado por Pereira e Dathein (2012), em que se analisou a influência do comportamento inovativo das grandes empresas da indústria de transformação brasileira a partir da base de dados das Pesquisas de Inovação Tecnológicas - Pintecs $(2000,2003,2005)$. Conforme os indicadores considerados, os autores concluíram que as empresas estrangeiras têm inovado a partir de relações intracorporativas em âmbito internacional e as empresas nacionais têm inovado relativamente menos, caracterizando-se como seguidoras das estratégias inovativas das empresas estrangeiras.

A segunda tendência fundamenta-se no estudo elaborado por Vargas e Zawislak (2006), na abordagem dos sistemas de inovação sobre a dimensão espacial. Os autores entendem que as investigações empíricas devem considerar uma dimensão espacial local ou regional - uma vez que o processo de aprendizagem, determinante do processo de inovação sob o paradigma do cenário pós-industrial, possui caráter delimitado geográfica, cultural e setorialmente e que está na fonte das vantagens competitivas das organizações.

Este estudo justifica-se pelo perfil empresarial brasileiro. Dados obtidos do Sebrae (SERVIÇO..., 2015a) apontavam a existência de 6,4 milhões de empresas no Brasil, entre as quais $99 \%$ eram micro e pequenas empresas (MPEs) e microempreendedores individuais (MEIs) que contribuíam com 27\% do PIB brasileiro (SERVIÇO..., 2015b).

Essa tendência vem se ampliando, como pode ser observado no portal da Internet, Empresômetro, que mantém atualizado um painel com o número de empresas ativas a todo momento no Brasil. É possível acompanhar a quantidade de empresas ativas no país nessa plataforma. Atualmente existem quase 21 milhões de empresas ativas, entre as quais apenas 31 mil (0,16\%) são empresas de capital aberto (S.A.). Assim, quase que a totalidade das empresas brasileiras são micro, pequenas e médias, cujos proprietários são responsáveis pela sua gestão. O número de microempreendedores individuais (MEls) cresce significativamente a cada ano, enquanto diminuem os empregos com carteira assinada. Entre as empresas ativas, 11,3 milhões (57\% do total) pertencem a essa categoria.

Desse modo, em um país em que predominam pequenas e médias empresas com baixa competência tecnológica, a melhor opção estratégica para o aumento da produtividade é a formação de redes, tais como os polos econômicos setoriais ou aquelas que se formam nos entornos das grandes corporações, por meio de parcerias.

O problema de pesquisa situa-se na busca de evidências se as corporações multinacionais contribuem para o aprimoramento da cadeia de valor por meio de inovações em gestão e, consequentemente para o desenvolvimento das localidades nas quais se estabelecem. Tendo em vista a interdisciplinaridade envolvida para se analisar o fenômeno delimitado no problema de pesquisa, foram estabelecidos dois objetivos específicos: 
(1) Construir um modelo teórico-metodológico para fundamentar as análises sobre a existência (ou não) de inovatividade em polos econômicos formados no entorno de grandes corporações multinacionais;

(2) Validar o modelo teórico-metodológico por meio de pesquisa empírica no polo econômico situado entre as regiões de Campinas e Sorocaba, onde existe grande concentração de empresas multinacionais.

Estruturado em cinco seções, incluindo a presente introdução, inicialmente é apresentada a fundamentação teórica que deu origem ao modelo conceitual de competências territoriais. Em seguida, buscou-se relacionar a literatura sobre inovações em gestão com os quatro determinantes das competências territoriais, fundamentando o modelo teórico-metodológico que norteou a pesquisa empírica. A quarta seção apresenta a metodologia de pesquisa empírica, seguida pelas análises dos resultados e considerações finais.

\section{COMPETÊNCIAS TERRITORIAIS NOS RELACIONAMENTOS ENTRE MULTINACIONAIS E PARCEIROS}

Ao longo das décadas de 90 e 2000, Porter $(1998,1999)$ ampliou a proposição inicial de vantagem competitiva sustentável (VCS), difundida na década de 80 , em que a competição não se resume única e exclusivamente às empresas, pois a vantagem competitiva sustentável extrapolou os contornos empresariais e se situa no conjunto de empresas que constituem as localidades, que por sua vez compõem as nações. Assim, Porter propõe a construção de um referencial para a compreensão da influência da localidade na competição que revela novos papéis para as empresas nesse novo contexto.

Porter e Stern (2002) elaboraram um estudo para investigar a influência da localização no desempenho das empresas e enfatizaram que a geografia também influi na capacidade de inovação das organizações. Os autores concluíram que as empresas que pretendem aumentar a competitividade devem se localizar em áreas de cluster, ou seja, aglomerados de empresas que lhes garantam inúmeras vantagens, que incluem desde mão de obra até fornecedores especializados.

Nesse sentido, Pitteri e Bresciani (2015) desenvolveram o conceito de "competências territoriais" a partir da noção de "vantagens específicas das localidades", proposta por Camagni (2002). Os autores promovem uma reorientação do conceito de "vantagens competitivas sustentáveis" (VCS), uma vez que essa expressão não faz muito sentido quando pensamos em regiões dentro dos países. Essa reorientação também está presente nos estudos de Pike, Rodríguez-Pose e Tomaney (2006), pois, no contexto globalizado, a competição para atrair e reter o capital móvel não deve sugerir que as localidades entrem em concorrência direta umas com as outras.

Em síntese, a fundamentação teórica de competências territoriais, proposta por Pitteri e Bresciani (2015), relaciona as proposições conceituais de Camagni (2002) no que se refere às vantagens específicas territoriais, incorporando os conceitos de capacidades dinâmicas de Araujo, Dubois e Gadde (2003), Argyres (1996), Barney e Clark (2007), Castro (2004), Conner (1991), Foss (1998, 2005), Langlois (1992), Makadok 
(2001), Peteraf (1993), Saes (2008), Teece, Pisano e Shuen (1997), Wernerfelt (1984) e, por fim, incorporam-se os conceitos sobre competências de Zarifian (1999) e Prahalad e Hammel (1988).

Esquema 1 - Vantagens específicas e competências territoriais

\begin{tabular}{|l|l|}
\hline \multicolumn{1}{|c|}{ Vantagens Específicas } & \multicolumn{1}{c|}{ Determinantes } \\
\hline Empresas & $\begin{array}{l}\text { Existência de empresas e organizações atuando como força motriz } \\
\text { no território para o desenvolvimento econômico. }\end{array}$ \\
\hline Governos locais e não-locais & $\begin{array}{l}\text { Existência de administração pública criativa e proativa capaz de } \\
\text { gerar sinergias inter-atores. }\end{array}$ \\
\hline Externalidades & $\begin{array}{l}\text { Existência de políticas públicas e investimentos que, se bem } \\
\text { articulados com os atores locais, são capazes de potencializar o } \\
\text { desenvolvimento da estrutura social de acumulação. }\end{array}$ \\
\hline Especificidades Territoriais & $\begin{array}{l}\text { Existência de especificidades territoriais construídas ao longo da } \\
\text { história por meio de regras e códigos comuns, desenvolvendo uma } \\
\text { cultura favorável para inovar, gerar conhecimento e difundir } \\
\text { aprendizagem coletiva. }\end{array}$ \\
\hline
\end{tabular}

\section{Competências Territoriais}

Existência de sistemas de governança, lideranças empresariais / institucionais que produzam:

(1) profundo comprometimento entre as pessoas para trabalhar além das fronteiras organizacionais;

(2) habilidade para lidar com imprevistos e incertezas, além de assegurar a capacidade rotineira da autorregulação;

(3) consciência coletiva de que os recursos devem ser preservados para não se esgotarem ao longo do tempo;

(4) clareza e transparência nas comunicações, especialmente nos processos de persuadir, negociar, coordenar e ensinar os parceiros envolvidos.

Fonte: PITTERI; BRESCIANI (2015, p. 251). não locais (sem hífen)/interatores (junto)

As vantagens específicas das localidades são formadas por empresas que atuam como força motriz no território para o desenvolvimento econômico; por uma administração pública criativa e proativa capaz de gerar sinergias entre os atores; por externalidades positivas promovidas por políticas públicas e investimentos que potencializem o desenvolvimento e, por fim, pelas especificidades territoriais, representadas por um conjunto de regras e hábitos desenvolvidos ao longo da História, criando uma cultura favorável para inovar, gerar conhecimento e difundir aprendizagem coletiva.

Os determinantes das vantagens específicas propostas por Camagni (2002), contudo, trazem, de modo implícito, a noção de equilíbrio estático, característica do corpo teórico das ciências econômicas. Alguns economistas ${ }^{3}$ vêm desenvolvendo estudos que alertam sobre a insuficiência das teorias econômicas para analisar o desempenho das organizações, situadas em ambientes de incerteza, interferindo diretamente nas suas dinâmicas. É necessário, portanto, que existam agentes de mudanças nas localidades que promovam transformações capazes de fazer frente às incertezas do ambiente macroeconômico globalizado.

\footnotetext{
${ }^{3}$ Araujo, Dubois e Gadde (2003), Argyres (1996), Barney e Clark (2007), Castro (2004), Conner (1991), Foss (1998, 2005), Langlois (1992), Makadok (2001), Peteraf (1993), Saes (2008), Teece, Pisano e Shuen (1997) e Wernerfelt (1984). Ver ref.
} 
A necessidade de se pensar os limites organizacionais em termos de capacidades que interagem com o meio apresentam pontos de contato com a noção de competências organizacionais, evoluindo para as competências que vão além da qualificação individual dos agentes de mudanças. Nesse sentido, destacam-se estudos recentes sobre competências como a que emerge na literatura francesa, nos estudos de Philippe Zarifian (1999), e na norte-americana com Prahalad e Hammel (1988), em que se procura ir além do conceito de qualificação individual das pessoas.

Zarifian (1999) destaca três elementos importantes na formação de competências na cadeia de valor dos sistemas pós-industriais. O primeiro é a noção de evento, ou seja, como as pessoas lidam com os imprevistos e incertezas. Isso implica que a competência vá além da capacidade rotineira de assegurar a autorregulação, característica dos sistemas fordistas. Desse modo, a competência não pode estar contida apenas na pessoa. O segundo é a comunicação, fundamental para compreender o outro e a si mesmo, ou seja, significa entrar em acordo sobre objetivos organizacionais, partilhar normas comuns para sua gestão. $O$ terceiro é a noção de serviço, que precisa ser uma função central e estar presente em todas as atividades.

A literatura norte-americana, representada por Prahalad e Hammel (1988), sugeriu a expressão core competences para designar as "competências essenciais" vinculadas às estratégias e aos objetivos organizacionais. Os autores concluem que a competência essencial é comunicação, envolvimento e um profundo comprometimento em se trabalhar além das fronteiras organizacionais. É necessário, portanto, que as pessoas consigam reconhecer as oportunidades de juntarem suas habilidades técnicas com as de outras pessoas, de forma que se criem novas e interessantes maneiras de se fazer as coisas.

A partir dos fundamentos apresentados, as competências territoriais formadas nos entornos das multinacionais devem se desenvolver a partir de quatro determinantes: (1) profundo comprometimento em se trabalhar além das fronteiras organizacionais; (2) habilidade para lidar com imprevistos e incertezas, assegurando a capacidade rotineira de autorregulação; (3) consciência coletiva de que os recursos devem ser preservados para não se esgotarem ao longo do tempo; (4) clareza e transparência nas comunicações, especialmente nos processos de persuadir, negociar, coordenar e ensinar os parceiros envolvidos.

Por sua vez, estudos recentes sobre inovações em gestão apresentam alguns pontos de contato entre o conceito de competências territoriais e comportamentos inovativos das empresas que se situam em polos econômicos.

O estudo elaborado por Pereira e Dathein (2012) apontou uma tendência de comportamento inovativo nas indústrias de transformação brasileiras a partir da base de dados das Pintecs $(2000,2003,2005)$. De acordo com os indicadores considerados, os autores concluíram que as empresas estrangeiras têm inovado, predominantemente, a partir de relações intracorporativas, de modo integrado ao âmbito internacional e, por sua vez, as grandes empresas nacionais têm inovado relativamente menos, caracterizando-se como seguidoras das estratégias inovativas das multinacionais. 
O segundo estudo, produzido por Vargas e Zawislak (2006), aborda os sistemas de inovação em uma dimensão espacial. Os autores entendem que as investigações empíricas devem considerar uma dimensão espacial, local ou regional, uma vez que o processo de aprendizagem, determinante do processo de inovação sob o paradigma do cenário pós-industrial, possui caráter delimitado geográfica, cultural e setorialmente e que está na fonte das vantagens competitivas das organizações. O ponto de partida da abordagem sistêmica, em contraponto ao modelo linear, é o entendimento do processo de inovação decorrente da aprendizagem coletiva, de natureza interativa, cujos aspectos técnicos guardam relevância, mas seus fundamentos baseiam-se em seu caráter social.

Nesse sentido, o presente estudo concentrou-se em buscar relações entre os determinantes das competências territoriais e inovações em gestão de empresas no polo econômico formado nos entornos da metrópole paulista, especialmente aquelas situadas entre as regiões administrativas de Campinas e Sorocaba, que vem sendo chamado informalmente de "corredor asiático", pelo intenso movimento de atração de grandes corporações asiáticas, motivado pelos altos investimentos em infraestrutura logística e grande concentração de universidades e centros de pesquisas, favorecendo a qualificação de mão de obra especializada.

\section{COMPETÊNCIAS TERRITORIAIS E INOVAÇÕES EM GESTÃO - DIMENSÕES PARA ANÁLISE}

Durante muito tempo a ideia de inovação esteve relacionada com as mudanças tecnológicas, porém atualmente já existe um consenso de que a inovação não se restringe à tecnologia aplicada. A Organização para a Cooperação e o Desenvolvimento Econômico (OCDE) reconheceu a importância das inovações não tecnológicas, corrigindo uma distorção mantida por mais de 50 anos em relação ao conceito, pois as inovações de mercado ou organizacionais constituem-se, muitas vezes, nas principais fontes de competitividade das empresas.

Zawislak (1996) fundamenta-se na economia evolucionária para ampliar o conceito de inovação, como sendo a capacidade das empresas em modificar continuamente sua própria estrutura diante de fatores aleatórios, ou seja, atividades imprevistas ou incertezas do ambiente que rondam a atividade de produção no nível das organizações, seja por impactos nos processos, na inovação tecnológica ou a aquisição de novos conhecimentos. Nesse sentido, as empresas criam uma atividade interna de buscar e aplicar novas soluções que, se bem-sucedidas, são incorporadas nas práticas de gestão, gerando sobrevivência, crescimento e resultados financeiros positivos.

Muitos estudos vêm sendo produzidos na tentativa de se propor uma teoria sobre as inovações não tecnológicas. O estudo de Vargas e Zawislak (2006) apresenta uma importante revisão da literatura sobre o assunto, porém os autores concluem que as questões postas pelo paradigma da economia do aprendizado ainda precisam ser integradas em uma abordagem teórica que concilie bens e serviços e, ao mesmo tempo, permita que o setor de serviços seja analisado em suas especificidades e em sua heterogeneidade. Tais características, de acordo com os autores, relacionam-se com aspectos insti- 
tucionais, culturais e geográficos, interferindo no fluxo das relações usuário-produtor, explicando a existência de peculiaridades de âmbito espacial, prioritariamente de plano nacional, mas também de âmbitos regionais ou locais.

No século passado o desafio residia em promover inovações na gestão dentro das empresas, porém no cenário pós-industrial a cadeia de valor estende-se para além das fronteiras das empresas e abrange, com frequência, comunidades inteiras. A tecnologia necessária para fazer coisas novas existe bem antes da mudança dos processos gerenciais, que vão se apropriar dessas tecnologias para inovar as práticas de gestão (HAMEL, 2006).

Desse modo, abre-se um campo interessante para proposições de modelos que possam contribuir com os fundamentos das inovações em gestão, em especial aquelas originadas por meio da interatividade entre os agentes envolvidos em determinado espaço geográfico. Os determinantes das competências territoriais relacionados às dimensões de análise e os temas abordados na pesquisa empírica foram sistematizados conforme esquema a seguir.

Esquema 2 - Modelo teórico-metodológico para análises empíricas

\begin{tabular}{|c|c|c|}
\hline Competências Territoriais & $\begin{array}{c}\text { Dimensões para } \\
\text { Análises }\end{array}$ & Temas abordados na Pesquisa Empírica \\
\hline $\begin{array}{l}\text { Profundo comprometimento para } \\
\text { trabalhar além das fronteiras } \\
\text { organizacionais }\end{array}$ & $\begin{array}{l}\text { Relações Eficazes entre } \\
\text { Empresas }\end{array}$ & $\begin{array}{l}\text { Contribuição da multinacional para a produção } \\
\text { de inovação em produtos, processos ou } \\
\text { serviços aos seus parceiros; } \\
\text { Divulgação pela multinacional de novas } \\
\text { tecnologias, novos produtos, novos processos } \\
\text { ou novas práticas de gestão; } \\
\checkmark \quad \text { Produção de inovações no modelo de negócio } \\
\text { para atender à(s) multinacional(is); } \\
\checkmark \quad \text { Inovações resultantes do trabalho conjunto } \\
\text { entre a multinacional e parceiros. } \\
\checkmark \begin{array}{l}\text { Processo de seleção de fornecedores e } \\
\text { parceiros; }\end{array}\end{array}$ \\
\hline $\begin{array}{l}\text { Habilidade para lidar com imprevistos e } \\
\text { incertezas, além de assegurar a } \\
\text { capacidade rotineira de auto-regulação }\end{array}$ & $\begin{array}{l}\text { Flexibilidade nas } \\
\text { práticas de gestão } \\
\text { internas e externas }\end{array}$ & $\begin{array}{l}\text { Existência ou não de flexibilidade dos parceiros } \\
\text { para atender novas solicitações de produtos ou } \\
\text { serviços da(s) multinacional(is); } \\
\text { Barreiras ou dificuldades dos parceiros para } \\
\text { atender novas solicitaçőes da(s) } \\
\text { multinacional(is). }\end{array}$ \\
\hline $\begin{array}{l}\text { Consciência coletiva de que os recursos } \\
\text { devem ser preservados para não se } \\
\text { esgotarem ao longo do tempo }\end{array}$ & $\begin{array}{l}\text { Preservação de } \\
\text { recursos esgotáveis e } \\
\text { do meio ambiente }\end{array}$ & $\begin{array}{l}\text { Produção de inovações em produtos, } \\
\text { processos, serviços ou práticas de gestão } \\
\text { voltadas para a preservação de recursos } \\
\text { esgotáveis ou do meio ambiente; } \\
\text { Identificação das inovações promovidas na sua } \\
\text { empresa para a preservação de recursos } \\
\text { esgotáveis e do meio ambiente. }\end{array}$ \\
\hline $\begin{array}{l}\text { Clareza e transparência nas } \\
\text { comunicaçőes, especialmente nos } \\
\text { processos de persuadir, negociar, } \\
\text { coordenar e ensinar os parceiros } \\
\text { envolvidos. }\end{array}$ & Aprendizagem Interativa & $\begin{array}{l}\checkmark \text { Geração e transferência de conhecimentos e } \\
\text { aprendizagem entre os parceiros e a(s) } \\
\text { multinacionais(s); } \\
\checkmark \quad \text { Como ocorre a geração e transferência de } \\
\text { conhecimento e aprendizagem interativa. }\end{array}$ \\
\hline
\end{tabular}

Fonte: Os autores (2017).

\section{METODOLOGIA DE PESQUISA}

Trata-se de um estudo teórico-empírico, de caráter exploratório, essencialmente qualitativo. No presente estudo optou-se por abordar as inovações em gestão, com foco nas empresas multinacionais e suas relações com os participantes da cadeia de valor. As dimensões abordadas foram: relações eficazes entre empresas; flexibilidade nas práticas de gestão internas e externas; preservação de recursos esgotáveis e do meio ambiente e aprendizagem interativa. 
A validação do modelo teórico-metodológico ocorreu por meio de pesquisa empírica, em que foram utilizados basicamente dois procedimentos metodológicos em três fases distintas. Na primeira foram entrevistados 7 parceiros de empresas multinacionais, cuja análise de conteúdo possibilitou a elaboração de um roteiro de pesquisa com questões estruturadas e/ou abertas.

$\mathrm{Na}$ segunda etapa foram selecionados 30 colaboradores e proprietários de empresas localizadas na região, extraídas de bases de dados de associados dos Centros das Indústrias do Estado de São Paulo (Ciesps) de Campinas e Sorocaba, Agências de Inovação de Campinas e Sorocaba (Inova Unicamp e Inova Sorocaba), universidades, matérias publicadas em jornais, revistas e sites da Internet, entre outros.

Por meio de envio de e-mails personalizados, as pessoas foram convidadas a responder um questionário, associado ao link da pesquisa intitulado Pesquisa sobre Inovação na Percepção de Fornecedores e Parceiros de Empresas Multinacionais. ${ }^{4}$ Houve um retorno de 40\%, totalizando 12 respondentes. Embora as tendências dos dados tenham permanecido mais ou menos constantes, foi necessário expandir a base de respondentes para garantir que ocorreu saturação das tendências dos dados e comentários em questões abertas.

A saturação em pesquisa qualitativa é um instrumento epistemológico que determina quando as observações deixam de ser necessárias, ou seja, quando nenhum elemento novo acrescenta propriedades ao objeto investigado, como escreve Thiry-Cherques (2009). O autor esclarece que o critério de saturação é uma dificuldade relevante em pesquisas qualitativas, pois a falta de recursos financeiros e tempo para a manutenção das observações ocorrem com frequência nas pesquisas empíricas. Desse modo, é necessário estabelecer um limite de tempo e quantidade de respostas, em virtude das tendências que vão se consolidando pelas próprias respostas.

A terceira etapa da pesquisa foi realizada a partir da ampliação das bases de dados dos respondentes, pois na segunda etapa observou-se que existem inúmeras empresas localizadas principalmente em São Paulo, que formam parcerias com empresas instaladas na região em estudo ou em outras localidades brasileiras. É o caso, por exemplo, da Unilever, que tem sua sede em Louveira, porém instala Centros de Distribuição em pontos estratégicos do país e forma parcerias com empresas localizadas em São Paulo. Desse modo, foram obtidas 32 respostas no total e a saturação das tendências ocorreu quando o banco de dados das respostas possuía 16 respostas válidas.

As três primeiras perguntas do questionário tiveram como finalidade caracterizar os respondentes em razão da natureza da sua empresa (nacional ou multinacional); da localização geográfica e se a organização mantém relacionamento com empresas multinacionais. Essas três questões serviram para eliminar as respostas inválidas ou que estavam fora do escopo da pesquisa. Das 32 respostas analisadas, foram excluídas 3: na primeira o questionário estava incompleto e as duas seguintes localizam-se fora

\footnotetext{
${ }^{4}$ O software utilizado para a pesquisa foi o Surveymonkey, que apresenta os requisitos de fidelidade e segurança adequados na coleta de dados. O link da pesquisa pode ser acessado apenas pelo destinatário da mensagem de correio eletrônico e somente uma resposta por respondente é registrada no banco de dados de coleta de respostas.
} 
do contexto da pesquisa. Das 29 respostas válidas, 16 delas mantêm relacionamentos com multinacionais, que foram analisadas a partir do modelo teórico-metodológico proposto.

Por se tratar de estudo exploratório, não foram efetuados recortes setoriais ou pelo porte de empresas, uma vez que as análises voltaram-se para compreender, de modo geral, os relacionamentos entre fornecedores e parceiros de empresas multinacionais localizadas em determinada região. Em uma seleção preliminar, optou-se por entrevistar colaboradores e parceiros de multinacionais nos setores de produtos químicos; tecnologia e informática; automobilístico; equipamentos eletrônicos; satélites e telecomunicações.

Os fornecedores e parceiros das multinacionais atuam em negócios ou setores distintos (complementares) de seus clientes, confirmando que os contornos das empresas vêm se expandindo e as relações entre parceiros vêm se tornando cada vez mais frequentes.

Os principais fornecedores/parceiros pesquisados atuam no negócio de trade marketing; em negócios imobiliários e gerenciamento de projetos de Arquitetura e Engenharia Civil; fornecedores de peças e equipamentos para a indústria automobilística; serviços de projetos em tecnologia e informática, consultorias em Gestão da Qualidade Total (GQT), soluções para satélites/telecomunicações e assessoria de imprensa.

\section{ANÁLISE DOS RESULTADOS}

Os temas propostos nas quatro dimensões de inovações em gestão, associadas aos determinantes das competências territoriais, foram analisados a partir do modelo teórico-metodológico e comparados com os achados empíricos.

\section{Relações Eficazes entre Empresas}

A existência de profundo comprometimento entre as pessoas para trabalhar além das fronteiras organizacionais envolve entender as conexões da empresa com o meio ambiente e as formas como os agentes de mudanças interagem entre si, levando-se em conta os arranjos institucionais já constituídos.

Nesse sentido, Besanko et al. (2012) escrevem que, nos últimos anos, as grandes empresas norte-americanas e europeias têm se focado cada vez mais em um conjunto essencial de atividades, terceirizando o restante para parceiros especializados nas atividades da cadeia vertical. Essas empresas estão seguindo as empresas do leste asiático, que vêm realizando parcerias colaborativas já há bastante tempo, pois consideram essa forma de atuação a maneira normal de se fazer negócios. Muitos produtores japoneses utilizam uma extensa rede de subcontratadas com quem mantêm um relacionamento de longo prazo com um nível de colaboração maior do que as empresas norte-americanas e europeias.

Essa diferença entre as culturas ocidentais e as asiáticas, manifestadas nas práticas de gestão, são importantes no entendimento de como as inovações são difundidas entre as partes, na medida em que as subcontratadas podem se envolver em projetos sofisticados e testes de protótipos em vez de atuarem apenas como fornecedores que atendem aos pedidos dos compradores. 
Com relação ao tema - contribuição das multinacionais na produção de inovação em produtos, processos ou serviços de seus fornecedores ou parceiros - não houve consenso nos dados empíricos. Metade dos entrevistados afirmou que sim, porém os demais apontaram que não ocorre ou que não têm certeza se as inovações produzidas em suas empresas são decorrentes de influências das multinacionais.

Alguns respondentes, contudo, trouxeram informações interessantes: "os clientes multinacionais têm grande participação no processo de construção de suas fábricas. Este procedimento melhora nosso entendimento de suas necessidades e incentiva a melhoria dos métodos executivos, controles de qualidade e cuidados com o meio ambiente"; "a automatização do processo produtivo e novas tecnologias são sempre trazidas de outros países"; "as adequações de produtos ao mercado brasileiro, a nacionalização de produtos importados e os custos cada vez menores, obrigam os parceiros a melhorar os projetos"; "algumas multinacionais possuem processos relacionados a seus fornecedores, onde a produção de documentação deve ser adaptada aos padrões globais para se criar uma uniformidade em toda informação produzida"; "usualmente, os padrões e métodos das multinacionais, nossas clientes, não modificam nosso produto, mas definitivamente ampliam nosso repertório e nosso horizonte para fornecimento de nossos serviços"; "aprendemos com exemplos de administração e visão de futuro".

A mesma tendência da questão anterior manteve-se com relação ao tema - divulgação pela multinacional de novas tecnologias, novos produtos, novos processos ou novas práticas de gestão. Os principais comentários foram os seguintes: "as montadoras japonesas, quando se instalaram no Brasil, capacitaram fornecedores nacionais para atender aos padrões de qualidade exigidos para o projeto"; "alguns produtos aplicáveis à parceria em andamento são informados" - neste quesito todos os esforços das multinacionais são para transferir os conhecimentos necessários e suficientes para o bom desempenho da nossa empresa em projetos conjuntos"; "faz parte do contexto do serviço prestado termos acesso ao funil de inovações da empresa".

Por outro lado, alguns respondentes apontaram para dificuldades na divulgação de novas tecnologias ou serviços, por questões regionais: "a divulgação de inovações pelas multinacionais está relacionada exclusivamente aos processos, mas ainda assim, algumas vezes esbarram na regionalidade imposta pela mão de obra brasileira"; "a multinacional libera o acesso à metodologia adotada porque é necessária para o nosso trabalho. Tivemos, contudo, que assinar um Termo de Confidencialidade e outros acessos foram vetados"; "no Brasil existem barreiras, principalmente comerciais, criando desafios e obstáculos importantes para a integração das operações de coordenação e controles, especialmente no caso dos nossos serviços, que envolvem o consumidor final dos produtos - as leis de defesa do consumidor no Brasil são muito mais rígidas do que em outros países emergentes, como a Índia, Rússia ou China - países em que nossa empresa atua, além do Brasil".

A tendência das respostas sobre o tema - inovações no modelo de negócio das fornecedoras ou parceiras para atender às multinacionais e/ou inovações resultantes do trabalho em conjunto com as multinacionais apresentou-se um pouco mais acentuada na resposta positiva. Dos 16 respondentes, 10 afirmaram que promoveram inovações no modelo de negócio para atender às multinacionais e 12 responderam afirmativamente que ocorreram inovações resultantes do trabalho conjunto. As multinacionais, 
que desenvolvem produtos de alta tecnologia, incentivam seus parceiros, por meio de suporte técnico e, às vezes financeiro, para nacionalizar os produtos: "nacionalizamos antenas transmissoras adequando a tecnologia desenvolvida nos Estados Unidos à matéria-prima encontrada no Brasil".

Nesse sentido, muitos respondentes associaram o tema às inovações em programas de qualidade, certificações ambientais ou metodologias de performance em gestão e TICs, tais como WCM - World Class Manufacturing; ACQUA e LEED; Analytics e Big Data; metodologia MEGplan.

Outros respondentes associaram as inovações conjuntas aos sistemas de informações estratégicas, com a finalidade de atender aos padrões internacionais da multinacional: "inovações na produção de relatórios e avaliação de benchmarking, intimamente relacionado a custos"; "processos desenvolvidos em outros países foram nacionalizados pela nossa empresa e hoje são fornecidos a vários clientes"; "melhoramos nossa gestão de processos"; "melhoramos alguns roteiros de trabalho".

Vale uma consideração importante na última questão sobre as formas de inovações conjuntas entre as multinacionais e seus parceiros. Nove dos 16 respondentes não encontraram alternativa no questionário e destacaram nos comentários das questões abertas que as inovações em gestão não requerem suporte técnico ou financeiro das multinacionais. Pode-se inferir, portanto, que as inovações em gestão dependem quase que exclusivamente da geração de conhecimento e aprendizagem coletiva, dependendo do grau de interatividade entre os parceiros e das relações e confiança e cooperação. Nesse sentido, a economia do conhecimento ganha valor em detrimento dos recursos tecnológicos ou financeiros, característica altamente positiva para os países emergentes, como o Brasil.

Por fim, os achados empíricos apresentaram três tendências principais na forma de contratação de fornecedores e parceiros pelas multinacionais. A tendência mais citada foi a concorrência formal baseada em critérios como: capacitação técnica, experiência em parcerias anteriores e preço adequado; a segunda, por indicação de colaboradores ou parceiros das multinacionais e a terceira (apenas dois casos) por meio de indicação da matriz da multinacional. Certas características nesses relacionamentos merecem algumas considerações.

Nas respostas espontâneas, a afirmativa recorrente foi a de que as empresas contratadas apresentaram os requisitos formais, como conhecimento técnico, equipe de profissionais capacitados e experiência anterior em outros projetos. Embora os entrevistados tenham afirmado que o preço foi o decisor principal, a "marca" ou a "grife" internacional (conforme palavras dos entrevistados e respondentes) aparentou ser um fator determinante na tomada de decisão, especialmente nas parcerias em serviços especializados, como no gerenciamento de projetos, marketing nos pontos de venda ou projetos de TICs.

Já no ramo automobilístico, possivelmente por se tratar de operações altamente estruturadas, os comentários foram: "todas as montadoras fazem a licitação para selecionar o fornecedor de melhor preço, porém existem parcerias estratégicas que acabam favorecendo fornecedores já consolidados, e o preço é renegociado". 
Dicken (2010) chama a atenção para as dificuldades encontradas pelas empresas globais ao se localizarem em outros países por conta das pressões por coordenação estratégica global versus a capacidade de resposta da localidade.

É possível, portanto, que as multinacionais levem em conta alguns fatores que Storper (1997) engloba na expressão untraded interdependencies (interdependências não comerciais), que tomam a forma de convenções, regras informais e hábitos que coordenam os atores econômicos em condições de incerteza. Essas relações constituem os ativos específicos regionais de produção. Esses ativos estão cada vez mais presentes no capitalismo contemporâneo e, portanto, uma forma central de diferenciação geográfica - no local em que é feito, como é feito e nos níveis de riqueza resultante e taxas de crescimento das localidades.

\section{Flexibilidade nas Práticas de Gestão Internas e Externas}

A habilidade para lidar com imprevistos e incertezas, além de assegurar a capacidade rotineira de autorregulação, traz, implícita, a necessidade de as empresas formarem equipes de trabalho para solucionar problemas contingenciais e criar projetos para desenvolver novos negócios, processos ou rotinas. As práticas de gestão altamente estruturadas, características das organizações industriais no contexto fordista, envolvem diversos níveis hierárquicos e não atendem às demandas de uma organização complexa e mutável inserida no contexto globalizado, como lembram Fleury e Fleury (2004).

Assim, a flexibilidade nas práticas de gestão, tanto internas quanto na interação com outras organizações, apresenta pontos de contato com a noção de modelagens organizacionais, como propõe Cavalcanti (2005). O autor lembra que esse recurso tem chamado a atenção dos estudiosos das organizações pela natureza contingencial, aparentemente necessária aos novos arranjos. Ele entende que a modelagem organizacional é um exercício cotidiano de improvisação, uma atividade contínua, dispersa, e depende muito mais da desenvoltura no manejo dos recursos do que dos recursos em si.

A tendência apontada na pesquisa empírica é a de que a flexibilidade interna e externa para atender às multinacionais vem se consolidando, na opinião da maioria dos entrevistados e respondentes da pesquisa. Nem todas as empresas, entretanto, atingiram o estágio desejado para atender às novas demandas das multinacionais. $\mathrm{O}$ caso das montadoras de veículos está bem consolidado, pois a decisão é tomada na matriz da multinacional e os fornecedores e parceiros cumprem as exigências, sempre.

As principais dificuldades apontadas por outros entrevistados foram: em alguns casos, o investimento em recursos necessários é muito elevado e a relação custo $\mathrm{x}$ benefício ficaria comprometida; a capacitação técnica da equipe é um fator relevante; a estrutura organizacional envolve vários níveis gerenciais na tomada de decisão; incerteza sobre os retornos financeiros comparados aos investimentos necessários. As empresas de alta tecnologia encontram algumas dificuldades associadas às incertezas do governo brasileiro, bem como ao sistema tributário: "a taxação de impostos no Brasil proíbe a adoção de algumas tecnologias que exigem a importação de partes e acessórios para a promoção das inovações. As incertezas no governo causam flutuações cambiais que dificultam a adoção de tecnologias que dependem de insumos importados". 
Vale lembrar, contudo, que mudanças nas práticas de gestão voltadas para aumentar a flexibilidade organizacional são difíceis de pôr em execução e, tanto no caso das modelagens organizacionais como na desverticalização, os agentes de mudanças são fundamentais para a concretização das equipes e para alcançar o desempenho desejado.

\section{Preservação de Recursos Esgotáveis e do Meio Ambiente}

A consciência coletiva de que os recursos devem ser preservados para não se esgotarem ao longo do tempo está relacionada diretamente à necessidade de as empresas promoverem mudanças continuamente, por meio da produção de inovações em produtos, processos e serviços, tendo em vista a importância crescente que as questões sociais e ambientais vêm ganhando ao longo das últimas décadas.

A tendência apontada em pesquisa empírica é que, embora a maioria dos respondentes tenha afirmado que suas empresas estão comprometidas "teoricamente", ainda não existem projetos inovadores significativos voltados para essa questão. Algumas informações espontâneas foram: "estamos estudando o uso de embalagens recicláveis e processos não poluentes na nossa produção"; "as multinacionais geralmente solicitam selos internacionais de reconhecimento de responsabilidade ambiental, mas nossa empresa não possui controle sobre estes selos"; "como empresa de consultoria, estamos conscientes da necessidade de preservação ambiental, porém somos consumidores modestos de recursos naturais".

A despeito do tema responsabilidade social e ambiental ter sido incorporado no discurso corporativo e nas respectivas campanhas publicitárias das empresas, os mecanismos de controle das práticas gerenciais voltadas para a preservação dos recursos esgotáveis e do meio ambiente ainda encontram-se em fase preliminar, tanto nos debates quanto nas práticas fiscalizatórias. Desde a década de 80 inúmeros organismos internacionais foram criados e vêm mobilizando setores públicos, privados e a sociedade civil organizada com o objetivo de se propor metas globais para minimizar os efeitos das desigualdades sociais e preservação de recursos esgotáveis e do meio ambiente.

No Brasil, a Constituição Federal de 1988 trata expressamente da questão ambiental de modo até então não concebido pelas Constituições precedentes, como escreve Silva (2011). A autora, entretanto, conclui que desenvolvimento econômico e preservação do meio ambiente ainda constituem um conflito insustentável na prática das organizações.

O meio ambiente está enquadrado no conceito de "macrobem", ou seja, bem de uso comum e de todos. Por conta dessa qualidade difusa, recebeu atenção especial da Constituição "no momento em que os povos despertam para a escassez de recursos naturais e para os efeitos nocivos da desenfreada evolução econômica e tecnológica, colocando em estado de alerta toda a humanidade" (SILVA, 2011, p. 146). A despeito do indiscutível avanço normativo sobre a questão ambiental, a autora conclui que a concretização dos princípios constituintes demanda esforços constantes do poder público para o cumprimento da função de fiscalizar. Os órgãos ambientais, responsáveis pela fiscalização e aplicação efetiva desse arcabouço legal, não escapam às deficiências que normalmente caracterizam a administração pública no país. 
Na prática, as instituições públicas deveriam desenvolver instrumentos econômicos em sintonia com a regulação direta, como estabelecer um custo para a utilização de um recurso natural, cuja redução possa se dar à medida que esta utilização predatória vá sendo minimizada. Carneiro (2003) cita a existência de alguns desses mecanismos, lamentando que sejam pouco utilizados no Brasil: tributos ambientais, sistemas de cobrança pelo uso de recursos ambientais, subsídios públicos, sistemas de devolução de depósitos, licenças ou créditos negociáveis e seguro ou caução ambiental.

Paralelamente, as empresas movimentaram-se para não permanecerem desatentas aos olhos vigilantes dos consumidores. O número dos chamados "consumidores verdes" nos países desenvolvidos cresceu significativamente, promovendo o repensar das empresas no que respeita à aceitação no mercado: como transformar em lucro a preocupação ambiental?

Em países em desenvolvimento como o Brasil, essa consciência por parte dos consumidores, embora crescente, ainda é reduzida. Em estudo realizado pela TNS/Interscience, em 2006, 51\% dos consumidores mencionaram que responsabilidade social e ambiental é importante, porém não se preocupam em investigar se o discurso da campanha publicitária está alinhado com a prática, ou seja, a forma e as condições em que os produtos foram produzidos (DANTAS; VIALLI, 2007).

Por fim, vale considerar que somente o poder público poderá atuar no combate às externalidades negativas do mercado, por meio de políticas públicas, incentivos fiscais, instrumentos econômicos e mecanismos de controle eficientes. A Constituição ampara a proposição de leis que estabeleçam limites às atividades corporativas e já existem iniciativas nesse sentido, contudo sem mecanismos de controle que resultem em multas ou qualquer punição, dificilmente as empresas tomarão iniciativas no sentido de preservar os recursos esgotáveis ou o meio ambiente.

\section{Aprendizagem Interativa}

Clareza e transparência nas comunicações, especialmente nos processos de persuadir, negociar, coordenar e ensinar os parceiros envolvidos deriva dos conceitos de capacidades dinâmicas proposta por Langlois (1992) e capacidades diretas (essenciais) e indiretas de Argyres (1996) e Araujo, Dubois e Gadde (2003). Para os autores, os limites das organizações não podem ser considerados sem que se leve em conta o processo de aprendizado, tanto no âmbito interno das empresas como nos mercados e territórios. Dessa forma, a fronteira da organização é uma decisão sobre como relacionar as capacidades próprias com as de outros agentes presentes no ambiente.

De acordo com o Manual de Oslo (2005), o gerenciamento do conhecimento é um aspecto importante no processo de inovação e compreende atividades relacionadas à apreensão, uso e compartilhamento do conhecimento pelas organizações parceiras. Elas abordam políticas e estratégias, liderança, apreensão de conhecimento, treinamentos e comunicações, assim como as razões para o uso das práticas de gerenciamento do conhecimento e os motivos por trás do desenvolvimento dessas práticas.

As tendências apontadas na pesquisa de campo confirmaram, na percepção de quase todos os respondentes, que a geração de conhecimento e aprendizagem interativa é um processo que vem se consolidando já há algum tempo. Apenas três res- 
pondentes afirmaram que aprendem muito com as multinacionais e ensinam pouco. Os comentários que se destacaram foram os que acreditam que as multinacionais estão na vanguarda do conhecimento de seus negócios, sempre aprimorando os produtos e processos com o objetivo de alcançar melhores resultados. Quando as atividades são mais complexas, as multinacionais criam centros de treinamento para capacitar seus fornecedores e parceiros.

Vale destacar, contudo, que em algumas áreas do conhecimento, como o caso do gerenciamento de projetos de Engenharia e Arquitetura ou serviços especializados em comunicação e gestão da qualidade, as empresas brasileiras contribuem de modo relevante para a aprendizagem das multinacionais, principalmente nas questões relacionadas à legislação brasileira, preservação do meio ambiente e às boas práticas construtivas, bastante avançadas no Brasil.

De acordo com os entrevistados, as empresas brasileiras aprendem muito com as multinacionais nas práticas de gestão, voltadas para a construção de CDs (Centros de Distribuição), porém as multinacionais aprendem muito com os fornecedores, construtoras e gerenciadoras de projetos, principalmente nos critérios e conceitos de preservação do meio ambiente. Isso acontece porque, na Engenharia, a realidade local gera barreiras para as multinacionais que não conhecem o mercado brasileiro com intimidade. "Neste ponto, não há dúvida que podemos contribuir mais".

Assim, a visão baseada em conhecimento concentra-se nos processos interativos em que o conhecimento é criado e trocado dentro e entre empresas e outras organizações. Muitas atividades, no entanto, não são baseadas em P\&D, ainda que dependam de trabalhadores capacitados, interações com outras empresas e instituições públicas de pesquisa e uma estrutura organizacional que conduz ao aprendizado e à exploração do conhecimento.

\section{CONSIDERAÇÕES FINAIS}

A análise de conteúdo dos achados empíricos sugere que o modelo teórico-metodológico proposto mostrou-se adequado para estudos futuros em polos econômicos em que as multinacionais se estabelecem, contribuindo para um melhor entendimento sobre suas relações com os respectivos parceiros e fornecedores.

Nas quatro dimensões analisadas foi possível observar que as especificidades locais, por exemplo, barreiras comerciais e regulatórias; existência de trabalhadores qualificados; leis de incentivos à inovação e aspectos culturais, entre outros fatores, influenciam diretamente a inovação na gestão da cadeia de valor.

Com relação aos setores de atividades dos parceiros das multinacionais, não foram efetuados recortes, uma vez que as análises voltaram-se para compreender, de modo geral, os relacionamentos entre fornecedores e parceiros de empresas multinacionais localizadas em determinada região. Os parceiros das multinacionais atuam em negócios distintos e complementares de seus clientes, confirmando que os contornos das empresas vêm se expandindo e as relações entre eles vêm se tornando cada vez mais abrangentes. 
Mesmo em setores de atividades distintos, entretanto, foi possível identificar padrões de conduta em inovações em gestão das empresas pesquisadas. Nos setores industriais, as relações na cadeia de valor encontram-se mais estruturadas e apresentam uma baixa dependência de inovações conjuntas entre as multinacionais e seus parceiros brasileiros. Em geral, as multinacionais definem quais as inovações necessárias para que os fornecedores e parceiros adotem, tanto nas especificações de produtos quanto de procedimentos, muitos deles voltados à gestão da qualidade total.

Já nos setores de serviços, principalmente os especializados, as relações entre as multinacionais e parceiros exigem maior flexibilidade nas práticas de gestão e alta dependência de inovações conjuntas. As empresas multinacionais contribuem para o aprimoramento das práticas de gestão das parceiras locais, porém estas também transferem conhecimento às multinacionais, especialmente nos aspectos relacionados aos mecanismos de fiscalização brasileiros, tais como leis ambientais, defesa do consumidor e métodos construtivos.

Com relação às práticas de gestão adotadas para a preservação de recursos esgotáveis e do meio ambiente, a tendência apontada em pesquisa empírica é que, embora a maioria dos respondentes tenha afirmado que suas empresas estão comprometidas "teoricamente", ainda não existem projetos inovadores significativos voltados para a sustentabilidade ambiental. Apesar de o tema responsabilidade social e ambiental ter sido incorporado no discurso corporativo e nas respectivas campanhas publicitárias das empresas, os mecanismos de controle voltados para a preservação dos recursos esgotáveis e do meio ambiente ainda se encontram em fase preliminar, tanto nos debates quanto nas práticas fiscalizatórias.

A despeito do indiscutível avanço normativo sobre a questão ambiental, a fiscalização demanda esforços constantes do poder público. Os órgãos ambientais, responsáveis pela fiscalização e aplicação efetiva desse arcabouço legal, não escapam às deficiências que normalmente caracterizam a administração pública no país. Somente o poder público poderá atuar no combate às externalidades negativas do mercado, por meio de políticas públicas, incentivos fiscais, instrumentos econômicos e mecanismos de controle eficientes. Sem eles, dificilmente as empresas tomarão iniciativas no sentido de preservar os recursos esgotáveis ou o meio ambiente.

Vale uma consideração importante sobre as formas de inovações conjuntas entre as multinacionais e seus parceiros. Nove dos 16 respondentes afirmaram nos comentários das questões abertas que as inovações em gestão não requerem suporte técnico ou financeiro das multinacionais. Pode-se inferir, portanto, que as inovações em gestão dependem quase que exclusivamente da geração de conhecimento e aprendizagem coletiva, dependendo do grau de interatividade entre os parceiros e das relações de confiança e cooperação. Nesse sentido, a economia do conhecimento ganha valor em detrimento dos recursos tecnológicos ou financeiros, característica altamente positiva para os países emergentes, como o caso brasileiro.

Por sua vez, as inovações em gestão escapam dos indicadores de produção de inovação, dos registros de patentes ou dos direitos de propriedade, prejudicando as análises quantitativas sobre o desempenho das empresas, ou, em casos mais graves, a quebra de contrato entre a multinacional e seus parceiros, quando o aprendizado torna-se explícito, estruturado e dependente de tecnologias disponíveis para todos. Essa 
fragilidade foi destacada por um dos entrevistados, em que a multinacional assimilou as tecnologias utilizadas no negócio da parceira, também multinacional. $O$ desdobramento dessa prática teve como reflexo a rescisão contratual da empresa parceira, que deixou de atuar no Brasil.

Desse modo, os contratos implícitos, ou seja, acordos não declarados entre as partes em um relacionamento, dependem muito mais do nível de confiança entre os parceiros, pois não poderão se amparar em instituições legais em casos de não cumprimento dos acordos.

Vale ressaltar que os achados do presente estudo não permitem generalizações sobre os padrões identificados, por algumas razões, entre as quais destacam-se as duas mais importantes. A primeira delas é a impossibilidade de se expandir os resultados de pesquisas realizadas em Campinas e Sorocaba para outras localidades, com características econômicas, sociais e culturais distintas das estudadas. Estudo realizado por Bresciani et al. (2013) aponta que as regiões de Campinas e Sorocaba foram identificadas como polos de inovação articulados e em consolidação e essas regiões apresentam características e especificidades territoriais distintas de outras realidades, impossibilitando que os achados dessa pesquisa possam ser adotados para outras localidades.

A segunda relaciona-se ao procedimento técnico de seleção das pessoas pesquisadas, que ocorreu por meio de amostra não probabilística, pela inexistência de bases de dados que representem o universo de todas as empresas fornecedoras ou parceiras das multinacionais na região estudada. Nesse sentido, foi feita uma tentativa de comunicação com o Instituto Brasileiro de Geografia e Estatística (IBGE), solicitando um recorte das empresas inovadoras por municípios, porém o IBGE esclareceu que o desenho amostral da Pintec não foi preparado para a divulgação de resultados no plano municipal.

Por fim, vale retomar a questão central do estudo e avaliar se as corporações multinacionais contribuem para o aprimoramento da cadeia de valor por meio de inovações em gestão. A partir das análises efetuadas, foi possível identificar que as multinacionais contribuem para as inovações em gestão de seus parceiros, porém, os parceiros também contribuem para o aumento de eficácia das clientes.

Para estudos futuros sugere-se a ampliação da pesquisa de campo para outras localidades que se caracterizam como polos econômicos no Estado ou no país a fim de se efetuar análises comparativas entre as localidades. A partir dessas referências abre-se um campo interessante para proposições de políticas públicas com foco nas realidades regionais, voltadas ao desenvolvimento sustentável.

\section{REFERÊNCIAS}

ARAUJO, L.; DUBOIS, A.; GADDE, L. The Multiple Boundaries of the Firm. Journal of Management Studies, v. 40, n. 5, p. 1.255-1.277, jul. 2003.

ARGYRES, N. S. Evidence on the role of firm capabilities in vertical integration decisions. Strategic Management Journal, v. 17, n. 2, p. 129-150, 1996.

BARNEY, J. B.; CLARK, D. N. Resource-Based Theory: Creating and Sustaining Competitive Advantage. Oxford; Nova York: Oxford University Press Inc., 2007. 316p.

BESANKO, D. et al. A economia da estratégia. Trad. Christiane de Brito. Revisão Herbert Kimura e Leonardo Fernando Cruz Basso. 5. ed. Porto Alegre: Bookman, 2012. 592 p. 
BRESCIANI, L. P. et al. Mecanismos de articulação territorial e a formação de polos de inovação na aglomeração industrial espacial (AIE) de São Paulo. Apoio Fapesp. Relatório final do projeto de auxílio pesquisa, processo n. 2011/51267-1.2013. Disponível em: <http://www.bv.fapesp.br/15296>.

CAMAGNI, R. On the Concept of Territorial Competitiveness: sound or misleading? Urban Studies, v. 39, n. 13, p. 1-23, 2002.

CARNEIRO, R. Direito ambiental: uma abordagem econômica. Rio de Janeiro: Forense, 2003. 162p.

CASTRO, A. C. Construindo pontes: inovação, organizações e estratégia como abordagens complementares. Revista Brasileira de Inovação, v. 3, n. 2, p. 449-473, 2004.

CAVALCANTI, B. S. O gerente equalizador. Estratégias de gestão no setor público. Rio de Janeiro: Ed. FGV, 2005. 280p.

CONNER, K. R. A historical comparison of resource-based theory and five schools of thought within industrial organization economics: do we have a new theory of the firm? Journal of Management, v. 17, n. 1, p. 121-154, 1991.

DANTAS, V.; VIALLI, A. Preocupação social nas compras. O Estado de São Paulo, B18, Negócios, 24 jan. 2007.

DEDECCA, C.; MONTALI, L.; BAENINGER, R. Regiões metropolitanas e pólos econômicos do Estado de São Paulo: desigualdades e indicadores para as Políticas Sociais. São Paulo: Finep; NEPP; Nepo; IE; Unicamp, mar. 2009.

DICKEN, P. Mudança global: mapeando as novas fronteiras da economia mundial. 5. ed. Trad. Teresa Cristina Felix de Souza. São Paulo: Bookman, 2010.

FLEURY, M. T. L.; FLEURY, A. C. C. Alinhando estratégias e competências. RAE-Revista de Administração de Empresas, v. 44, n. 1, p. 44-57, 2004.

FOSS, Nicolai J. The Resource-Based Perspective: An assessment and diagnosis of problems. Scandinavian Journal of management, v. 14, n. 3, p. 133-149, 1998.

Strategy, economic, organization and knowledge economy: The coordination of firms and resources. Oxford: Oxford University Press, 2005.

HAMEL, Gary. O laboratório de inovação em gestão. HSM Management, n. 58, p. 121-124, set./out. 2006. LANGLOIS, R. N. Transaction-cost Economics in Real Time. Industrial and Corporate Change, v. 1, n. 1, p. 99-127, 1992.

MAKADOK, R. Toward a synthesis of the resource-based and dynamic-capability views of rent creation. Strategic Management Journal, v. 22, p. 387-401, 2001.

MANUAL DE OSLO. Diretrizes para coleta e interpretação de dados sobre inovação. 3. ed. OECD; Finep, 2005.

PRAHALAD, C. K; HAMMEL, G. A competência essencial da corporação. In: MONTGOMERY, C. A.; PORTER, M. E. (Org.). Estratégia: a busca da vantagem competitiva. Rio de Janeiro: Campus, 1998. p. 293-316.

PEREIRA, A. J.; DATHEIN, R. Sistema Nacional de Inovações e comportamento inovativo das grandes empresas nacionais e estrangeiras da indústria de transformação brasileira. Porto Alegre: UFRGS; FCE; Deri, 2012. Ordem alf.

PETERAF, Margaret A. The Cornerstones of Competitive Advantage: A Resource-Based View. Strategic Management Journal, v. 14, p. 179-191, 1993.

PIKE, Andy; RODRÍGUEZ-POSE, Andrés; TOMANEY, John. Local and Regional Development. New York: Routledge, 2006. 310 p.

PIKE, Andy; RODRÍGUEZ-POSE, Andrés; TOMANEY, John (Ed.). Handbook of Local and Regional Development. London and New York: Routledge, 2011.

PESQUISA DE INOVAÇÃO TECNOLÓGICA (Pintec). Pesquisa de Inovação. Bancos de Dados. 2000, 2003, 2005. Disponível em: <www.pintec.ibge.gov.br>.

PITTERI, S.; FELDMANN, P. R.; BRESCIANI, L. P. As condições globais-locais e os grupos transnacionais: uma análise do cenário pós-industrial e suas implicações para a internacionalização de empresas. Ensaios FEE, Porto Alegre, v. 35, n. 1, p. 101-122, jun. 2014.

PITTERI, S.; BRESCIANI, L. P. Competências territoriais em perspectivas teóricas e empíricas: o caso do Complexo Portuário de Santos, SP. Revista Brasileira de Gestão e Desenvolvimento Regional, v. 11, n. 1, p. 243-272, jan./abr. 2015, Taubaté, SP, Brasil.

PORTER, M. E.; STERN, S. Inovação e localização de mãos dadas. HSM Management, n. 30, p. 118-125, jan./fev. 2002.

PORTER, M. E. How Competitive Forces Shape Strategy. Harvard Business Review, p. 137-156, mar./abr. 1979. 
PORTER, M. E. Clusters and the New Economics of Competition. Harvard Business Review, Reprint 98.609, p. 77-90, 1998.

. Competição $=$ On Competition: estratégias competitivas essenciais. Trad. Afonso Celso Serra. 10. ed. Rio de Janeiro: Ed. Campus, 1999. 515 p.

SAES, M. S. M. Diferenciação e apropriação da quase-renda na agricultura: a cafeicultura de pequena escala. Tese (Livre Docência) - Faculdade de Economia e Administração, Universidade de São Paulo, 2008. $162 \mathrm{p}$.

SERVIÇO DE APOIO ÀS MICRO E PEQUENAS EMPRESAS (Sebrae). Onde estão as micro e pequenas empresas no Brasil. Disponível em: <http://www.sebraesp.com.br/arquivos_site/biblioteca/EstudosPesquisas/ mpes_numeros/onde_mpes_brasil.pdf>. Acesso em: 13 jun. 2015a.

Micro e pequenas empresas geram 27\% do PIB do Brasil. Disponível em: <http://www.sebrae. com.br/sites/PortalSebrae/ufs/mt/noticias/Micro-e-pequenas-empresas-geram-27\%25-do-PIB-do-Brasil>. Acesso em: 13 jun. 2015b.

SILVA, M. S. Desenvolvimento econômico versus meio ambiente: um conflito insustentável. Economic Development versus Environment: one Conflict Unbearable. Hiléia: Revista do Direito Ambiental da Amazônia, n. 16, p. 143-157, jan./jun. 2011.

STORPER, Michael. The regional world: territorial development in a global economy. New York; London: The Guilford Press, 1997. 338p.

TEECE, D. J.; PISANO, G.; SHUEN, A. Dynamic Capabilities and Strategic Management. Strategic Management Journal, v. 18, n. 7, p. 509-533, ago. 1997.

THIRY-CHERQUES, H. R. Saturação em pesquisa qualitativa: estimativa empírica de dimensionamento. Af-Revista PMKT, p. 20-27, 2009.

VARGAS, E. R.; ZAWISLAK, P. A. Inovação em serviços no paradigma da economia do aprendizado: a pertinência de uma dimensão espacial na abordagem dos sistemas de inovação. RAC, v. 10, n. 1, p. 139-159, jan./mar. 2006.

ZARIFIAN, Philippe. La compétence en débat: Présentation de l'ouvrage de Philippe Zarifian, Objectif compétence [note critique]. Damien Brochier. Formation Emploi, v. 67, n. 1, p. 137-140, 1999.

ZAWISLAK, P. A. Uma abordagem evolucionária para análise de casos de inovação no Brasil. Ensaios FEE, Porto Alegre, v. 17, n. 1, p. 323-354, 1996.

WERNERFELT, B. A resource-based view of the firm. Strategic Management Journal, v. 5, p. 171-180, 1984. 